City University of New York (CUNY)

CUNY Academic Works

Economics Working Papers

CUNY Academic Works

2015

Estimating the Variance of Decomposition Effects

Takuya Hasebe

Sophia University

Follow this and additional works at: https://academicworks.cuny.edu/gc_econ_wp

Part of the Economics Commons

How does access to this work benefit you? Let us know!

More information about this work at: https://academicworks.cuny.edu/gc_econ_wp/2

Discover additional works at: https://academicworks.cuny.edu

This work is made publicly available by the City University of New York (CUNY).

Contact: AcademicWorks@cuny.edu 


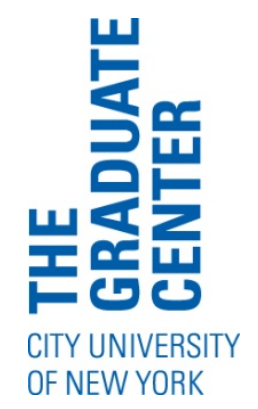

CUNy Graduate Center Ph.D Program in Economics WORKING PAPER SERIES

\section{Estimating the Variance of Decomposition Effects}

Takuya Hasebe

Working Paper 6

Ph.D. Program in Economics

CUNY Graduate Center

365 Fifth Avenue

New York, NY 10016

April 2015

(C) 2015 by Takua Hasebe. All rights reserved. Short sections of text, not to exceed two paragraphs, may be quoted without explicit permission provided that full credit, including (c) notice, is given to the source. 
Estimating the Variance of Decomposition Effects

Takua Hasebe

April 2015

JEL No: C10, J70

\begin{abstract}
We derive the asymptotic variance of Blinder-Oaxaca decomposition effects. We show that the delta method approach that builds on the assumption of fixed regressors understates true variability of the decomposition effects when regressors are stochastic. Our proposed variance estimator takes randomness of regressors into consideration. Our approach is applicable to both the linear and nonlinear decompositions, for the latter of which only a bootstrap method is an option. As our derivation follows the general framework of m-estimation, it is straightforward to extend to the cluster-robust variance estimator. We demonstrate the finite-sample performance of our variance estimator with a Monte Carlo study and present a real-data application.
\end{abstract}

Takuya Hasebe

Faculty of Liberal Arts, Sophia University

7-1 Kioi-cho, Chiyoda-ku

Tokyo 102-8554, Japan

thasebe@sophia.ac.jp 


\section{Introduction}

Since the influential seminar works by Blinder (1973) and Oaxaca (1973), the decomposition method has been used to analyze racial, gender, and intertemporal differences and more. In addition to the original linear model to decompose wages, the method has been extended to nonlinear models to analyze limited dependent variables such as binary and count data outcomes. The decomposition method became a popular tool in empirical studies not only in labor economics but also in other areas such as health economics. Fortin et al. (2011) provides an excellent survey of the decomposition method. Moreover, the recent discussion about the connection to the literature of treatment effects (Fortin et al., 2011; Kline, 2011) makes the decomposition method a even more valuable tool for applied researchers.

Although the decomposition method has been used for a long time, it is relatively recently that statistical inference of the decomposition analysis has been discussed. In early times, results of the decomposition analysis were presented without standard errors. Oaxaca and Ransom (1998) propose the variance estimator derived by the delta method. However, it builds on the implicit assumption of fixed regressors. When regressors are stochastic, which is a more plausible assumption in most empirical studies, the delta method variance tends to overstate statistical significance by ignoring the variability of regressors. Jann (2008) suggests a variance estimator with stochastic regressors for the linear decomposition. Kline (2014) also derives the asymptotic distribution of a variant of the linear decomposition and shows that ignoring of the variability of regressors results in incorrect inference.

The primary contribution of this paper is to derive the asymptotic variance of the nonlinear decomposition, which is also applicable to the linear decomposition. For nonlinear

models, as Fortin et al. (2011) suggest, only a bootstrap approach has been a valid option. However, the bootstrap estimation of the variance is often computationally demanding. Therefore, the analytical variance estimator of nonlinear models must be of practical use for 
applied researchers. Monte Carlo experiments demonstrate that our proposed variance estimator indeed leads to correct statistical inference. A real-data application also show that our variance estimates are almost identical to the bootstrap estimates.

Secondly, since our derivation of the asymptotic variance is based on the general framework of m-estimation, it is easily extendable to various settings. As an example, we extend our variance estimator to a cluster-robust variance following Cameron et al. (2011). Our Monte Carlo study shows that our variance estimator performs well even in the presence of clustering correlation. In addition, the analytical variance is essential to obtain asymptotic refinement through the bootstrap method for more reliable inference Cameron et al. (2008).

The rest of this paper is organized as follows. In the next section, we introduce the decomposition analysis. Section 3 discusses the estimator of the decomposition effects and derives the asymptotic distribution. ection 4 presents results of a Monte Carlo study, followed by a real-data application in Section 5. Section 6 concludes.

\section{Decomposition Analysis}

This section introduces the decomposition analysis. Our focus is the decomposition in the mean of outcome. See Fortin et al. (2011) for recent developments of the decomposition beyond the mean.

Let $y_{i}$ be an outcome of interest and let $d_{i}$ be an indicator of group such as race and gender, $d_{i}=0,1$, for an observation $i, i=1, \ldots, N$. The decomposition can be written as

$$
E\left[y_{1 i} \mid d_{i}=1\right]-E\left[y_{0 i} \mid d_{i}=0\right]=\left\{E\left[y_{1 i} \mid d_{i}=1\right]-E\left[y_{0 i} \mid d_{i}=1\right]\right\}+\left\{E\left[y_{0 i} \mid d_{i}=1\right]-E\left[y_{0 i} \mid d_{i}=0\right]\right\}
$$

where the subscript indicates a potential outcome. We observe $y_{i}=d_{i} y_{1 i}+\left(1-d_{i}\right) y_{0 i}$. The decomposition involves counterfactual expectation $E\left[y_{0 i} \mid d_{i}=1\right]$, which expresses an expected outcome if an individual in one group $\left(d_{i}=1\right)$ were treated as if in the other group $\left(d_{i}=0\right)$. 
By the law of iterated expectation, $E\left[y_{j i} \mid d_{i}=k\right]=E\left[E\left(y_{j i} \mid x_{i}, d_{i}=k\right) \mid d_{i}=k\right]$ for $j=0,1$ and $k=0,1$. Furthermore, under the conditional independence assumption, $E\left[y_{j i} \mid x_{i}, d_{i}=k\right]=$ $E\left[y_{j i} \mid x_{i}\right]$. This assumption holds for the decomposition analysis since being a particular gender or race is obviously predetermined. Now the expectation conditional on $x_{i}$ is assumed to be a parametric function of $x_{i}$ with a parameter vector $\beta_{j}: E\left[y_{j i} \mid x_{i}\right]=F\left(x_{i} ; \beta_{j}\right)$. For instance, the OLS decomposition specifies $F\left(x_{i} ; \beta_{j}\right)=x_{i}{ }^{\prime} \beta_{j}$. In this case, the first curly bracket in the right-hand of the equation (1) is $E\left[y_{1 i} \mid d_{i}=1\right]-E\left[y_{0 i} \mid d_{i}=1\right]=E\left[x_{i} \mid d_{i}=1\right]^{\prime}\left(\beta_{1}-\beta_{0}\right)$, which is the difference due to different effects of observable characteristics. This term is referred to as a coefficient effect. It can also be interpreted as the average treatment effect on the treated under certain conditions. The second bracket is $E\left[y_{0 i} \mid d_{i}=1\right]-E\left[y_{0 i} \mid d_{i}=0\right]=$ $\left(E\left[x_{i} \mid d_{i}=1\right]-E\left[x_{i} \mid d_{i}=0\right]\right)^{\prime} \beta_{0}$, which is the difference due to differences in the characteristics, which is referred to as an endowment effect. When the reference group is switched to $d_{i}=0$, the difference can alternatively be decomposed as

$E\left[y_{1 i} \mid d_{i}=1\right]-E\left[y_{0 i} \mid d_{i}=0\right]=\left\{E\left[y_{1 i} \mid d_{i}=0\right]-E\left[y_{0 i} \mid d_{i}=0\right]\right\}+\left\{E\left[y_{1 i} \mid d_{i}=1\right]-E\left[y_{1 i} \mid d_{i}=0\right]\right\}$,

of which the first and second curly brackets measure the coefficient and endowment effects, respectively.

Several nonlinear decomposition models are proposed: for example, probit and logit models (Fairle, 2006), Tobit model (Bauer and Sinning, 2010), and count data models (Bauer et al., 2007). Bauer and Sinning (2008) also discuss other nonlinear models. For example, for the probit model, $F\left(x_{i} ; \beta_{j}\right)=\Phi\left(x_{i}^{\prime} \beta_{j}\right)$, where $\Phi(\cdot)$ is the cdf of standard normal. For the Tobit model with the outcome left-censored at 0 , the conditional expectation function is $x_{i}{ }^{\prime} \beta_{j} \Phi\left(x_{i}{ }^{\prime} \beta_{j}\right)+\sigma_{j} \phi\left(x_{i}{ }^{\prime} \beta_{j}\right)$, where $\phi(\cdot)$ is the pdf of standard normal. Note that the conditional expectation involves the parameter $\sigma_{j}$, the standard deviation

\footnotetext{
${ }^{1}$ See Kline (2011) for the conditions under which this term has a causal interpretation.
} 
of a disturbance term, in addition to the coefficient vector $\beta_{i}$. For count data models, it is occasionally necessary to solve the problem of excess zeros using zero-inflated or hurdle models. The conditional expectation function of the hurdle negative binomial model is $\exp \left(x_{i}{ }^{\prime} \beta_{j}\right) /\left\{\left(1-\left(1+\alpha_{j} \exp \left(x_{i}{ }^{\prime} \beta_{j}\right)\right)^{-1 / \alpha_{j}}\right)\left(1+\exp \left(z_{i}^{\prime} \gamma_{j}\right)\right)\right\}$, where $\alpha_{j}$ is the dispersion parameter. The regressors $x_{i}$ affect positive counts of outcome while $z_{i}$ governs the probability that zero counts occur. These regressors may or may not be identical. Hereafter, we generalize the notation of conditional expectation functions to $F\left(w_{i} ; \theta_{j}\right)$, where $w_{i}$ is a vector of all regressors and $\theta_{j}$ is a vector of all parameters. See Appendix $\mathrm{B}$ for the specified functional forms of $F\left(w_{i} ; \theta_{j}\right)$ for the models considered in this paper.

As shown in the equation (1), the decomposition effects can be expressed as linear combinations of the conditional expectations. Let $\mu$ be a vector with four elements, each of which is defined as follows:

$$
\mu=\left(\begin{array}{l}
\mu_{11} \\
\mu_{01} \\
\mu_{10} \\
\mu_{00}
\end{array}\right)=\left(\begin{array}{c}
E\left[y_{1 i} \mid d_{i}=1\right] \\
E\left[y_{0 i} \mid d_{i}=1\right] \\
E\left[y_{1 i} \mid d_{i}=0\right] \\
E\left[y_{0 i} \mid d_{i}=0\right]
\end{array}\right)=\left(\begin{array}{c}
E\left[F\left(w_{i} ; \theta_{1}\right) \mid d_{i}=1\right] \\
E\left[F\left(w_{i} ; \theta_{0}\right) \mid d_{i}=1\right] \\
E\left[F\left(w_{i} ; \theta_{1}\right) \mid d_{i}=0\right] \\
E\left[F\left(w_{i} ; \theta_{0}\right) \mid d_{i}=0\right]
\end{array}\right)
$$

Then, the coefficient effect is $\mu_{11}-\mu_{01}$. In matrix notation, it can be written as $R_{c} \mu$, where $R_{c}=(1,-1,0,0)$. Given the variance of $\widehat{\mu}, V(\widehat{\mu})$, the variance of the coefficient effect is $R_{c} V(\widehat{\mu}) R_{c}^{\prime}$. Likewise, the variance of the endowment effect, $\mu_{01}-\mu_{00}$, is computed as $R_{e} V(\widehat{\mu}) R_{e}^{\prime}$ by setting $R_{e}=(0,1,0,-1)^{\prime}$, and the variances of those effects with switched references can also be obtained by modifying $R_{c}$ and $R_{e}$. Therefore, estimating the variance of the decomposition effects is reduced to the estimation of variance of $\widehat{\mu}$.

The estimation of $\mu$ is straightforward. We estimate $\theta_{j}$ from relevant samples and compute the conditional expectation functions with relevant estimates and samples. However, 
estimating its variance is not as straightforward. Oaxaca and Ransom (1998) discuss the delta method approach under the implicit assumption of fixed regressors. This approach accounts for the variability of $\widehat{\theta}_{j}$. When regressors $x_{i}$ are stochastic, however, it is inappropriate. To think of this point concretely, consider the coefficient effect in the linear decomposition. As shown above, it is $E\left[x_{i} \mid d_{i}=1\right]^{\prime}\left(\beta_{1}-\beta_{0}\right)$. In order to estimate this effect, we need to estimate $E\left[x_{i} \mid d_{i}=1\right]$ as well as $\beta_{0}$ and $\beta_{1}$. While the delta method approach takes into account the fact that $\beta_{0}$ and $\beta_{1}$ are estimated, it does not take into account the fact that $E\left[x_{i} \mid d_{i}=1\right]$ is estimated.

Jann (2008) discusses the variance estimator that accounts for the variability of regressors for the linear decomposition. However, as shown below, his approach cannot extend to the nonlinear decompositions directly. Kline (2014) also derives the variance of the linear decomposition, but only the coefficient effect. For the nonlinear decompositions, the bootstrap inference is an option for applied researchers as Fortin et al. (2011) suggest.2 Although it is useful, the bootstrap approach is computationally intensive, especially when a model is highly nonlinear and/or a sample size is large. An analytical variance estimator is computationally much less intensive. Moreover, an analytical variance estimator is essential in order to obtain asymptotic refinement through the bootstrap methods (Horowitz, 2001).

In the next section, we describe the estimation of $\mu$ and derive its asymptotic variance. The derivation starts by noting that the estimation of $\mu$ involves sequential steps. Then, we follow the derivation of the variance of sequential m-estimation. The framework of the m-estimation enables us to extend to the cluster-robust variance easily.

\footnotetext{
${ }^{2}$ For example, Bauer et al. (2007) and Bauer and Sinning (2008, 2010) report the bootstrap standard errors.
} 


\section{Estimation}

\subsection{Estimation of $\mu$}

The estimation of $\mu$ involves two steps sequentially. The first step estimates the parameters of the conditional expectation functions, $\theta=\left(\theta_{1}{ }^{\prime}, \theta_{0}{ }^{\prime}\right)^{\prime}$ by OLS or MLE (or generally mestimation). At the second step, we estimate $\mu$ using the estimated parameters $\widehat{\theta}$. When deriving the asymptotic variance of $\widehat{\mu}$, it is necessary to take into account the fact that $\theta$ is estimated at the first step.

At the first step, $\theta$ is estimated by solving the equations:

$$
N^{-1} \sum_{i=1}^{N} h_{\theta i}(\theta)=0
$$

where $h_{\theta i}(\theta)$ is a vector defined as

$$
h_{\theta i}(\theta)=\left(\begin{array}{c}
d_{i} s_{1}\left(y_{i}, w_{i} ; \theta_{1}\right) / \tau_{1} \\
\left(1-d_{i}\right) s_{0}\left(y_{i}, w_{i} ; \theta_{0}\right) / \tau_{0}
\end{array}\right) \text {, }
$$

where $\tau_{1}$ and $\tau_{0}$ are $\operatorname{Pr}\left(d_{i}=1\right)$ and $\operatorname{Pr}\left(d_{i}=0\right)$, respectively $\left.\right|^{3}$ For OLS, $s_{j}\left(y_{i}, w_{i}, \theta_{j}\right)=$ $x_{i}\left(y_{i}-x_{i}{ }^{\prime} \beta_{j}\right)$, and for MLE, $s_{j}\left(y_{i}, w_{i}, \theta_{j}\right)=\partial \ln L_{i}\left(\theta_{j}\right) / \partial \theta_{j}$, where $\ln L_{i}\left(\theta_{j}\right)$ is the contribution to the log likelihood by an observation $i$. The equation (3) is the first order conditions for an m-estimation of $\theta .4$ This step is equivalent to estimating $\theta_{j}$ with a corresponding sample separately.

\footnotetext{
${ }^{3}$ Precisely speaking, the probabilities $\tau_{1}$ and $\tau_{0}$ are also estimated by $\widehat{\tau}_{1}=N^{-1} \sum_{i=1}^{N} d_{i}$ and $\widehat{\tau}_{0}=$ $N^{-1} \sum_{i=1}^{N}\left(1-d_{i}\right)$. However, it is not necessary to account for the variability from the estimation of these probabilities. See Appendix A for details.

${ }^{4}$ Clearly, we can interpret our estimation procedure as an estimating equation estimator.
} 
The second step estimates $\mu$ by solving the sample counterpart of the equation (2):

$$
N^{-1} \sum_{i=1}^{N} h_{\mu i}(\mu, \widehat{\theta})=0
$$

where $h_{\mu i}(\mu, \theta)$ is defined as

$$
h_{\mu i}(\mu, \theta)=\left(\begin{array}{c}
d_{i}\left(F\left(w_{i} ; \theta_{1}\right)-\mu_{11}\right) / \tau_{1} \\
d_{i}\left(F\left(w_{i}, \theta_{0}\right)-\mu_{01}\right) / \tau_{1} \\
\left(1-d_{i}\right)\left(F\left(w_{i} ; \theta_{1}\right)-\mu_{10}\right) / \tau_{0} \\
\left(1-d_{i}\right)\left(F\left(w_{i} ; \theta_{0}\right)-\mu_{00}\right) / \tau_{0}
\end{array}\right) .
$$

It is equivalent to computing the conditional expectations with relevant samples and estimated parameters. The fact that $\theta$ is estimated at the first step needs to be taken into account in deriving the asymptotic variance of $\widehat{\mu}$.

Proposition 1 Under the regular conditions, we have the asymptotic distribution of $\widehat{\mu}$ as follows:

$$
\sqrt{N}(\widehat{\mu}-\mu) \stackrel{d}{\rightarrow} \mathcal{N}(0, V(\widehat{\mu}))
$$

The asymptotic variance $V(\widehat{\mu})$ is

$$
V(\widehat{\mu})=S_{\mu \mu}+G_{\mu \theta} V(\widehat{\theta}) G_{\mu \theta}{ }^{\prime}
$$


where $V(\widehat{\theta})$ is the asymptotic variance of $\widehat{\theta}$, and

$$
\begin{aligned}
G_{\mu \theta} & =\lim N^{-1} \sum_{i=1}^{N} E\left[\partial h_{\mu i}(\mu, \theta) / \partial \theta^{\prime}\right] \\
& =\lim N^{-1} \sum_{i=1}^{N} E\left[\begin{array}{cc}
d_{i}\left(\partial F\left(w_{i} ; \theta_{1}\right) / \partial \theta_{1}{ }^{\prime}\right) / \tau_{1} & 0 \\
0 & d_{i}\left(\partial F\left(w_{i} ; \theta_{0}\right) / \partial \theta_{0}{ }^{\prime}\right) / \tau_{1} \\
\left(1-d_{i}\right)\left(\partial F\left(w_{i} ; \theta_{1}\right) / \partial \theta_{1}{ }^{\prime}\right) / \tau_{0} & 0 \\
0 & \left(1-d_{i}\right)\left(\partial F\left(w_{i} ; \theta_{0}\right) / \partial \theta_{0}{ }^{\prime}\right) / \tau_{0}
\end{array}\right]
\end{aligned}
$$

and

$$
S_{\mu \mu}=\lim N^{-1} \sum_{i=1}^{N} E\left[h_{\mu i}(\mu, \theta) h_{\mu i}(\mu, \theta)^{\prime}\right]
$$

See Appendix A for the proof.

The term $G_{\mu \theta} V(\widehat{\theta}) G_{\mu \theta}{ }^{\prime}$ corresponds to the delta method approach. The matrix $S_{\mu \mu}$ represents variability due to variation in $w_{i}$, which would arise even if the true value of $\theta$ were known. Since $S_{\mu \mu}$ is a positive definite matrix, the variance estimator based on the delta method approach understates the true variance. Put it differently, ignoring the variation in $w_{i}$ results in underestimation of $V(\widehat{\mu})$.

We estimate $V(\widehat{\mu})$ by

$$
\widehat{V}(\widehat{\mu})=N^{-1} \sum_{i=1}^{N} \widehat{h}_{\mu i} \widehat{h}_{\mu i}{ }^{\prime}+\left(N^{-1} \sum_{i=1}^{N} \partial h_{\mu i} /\left.\partial \theta^{\prime}\right|_{\theta=\widehat{\theta}}\right) \widehat{V}(\widehat{\theta})\left(N^{-1} \sum_{i=1}^{N} \partial h_{\mu i} /\left.\partial \theta^{\prime}\right|_{\theta=\widehat{\theta}}\right),
$$

where $\widehat{h}_{\mu i}=h_{\mu i}(\widehat{\theta})$.

One of the concerns regarding statistical inference that empirical researchers often face is correlation within cluster. It is well-known that ignoring clustering tends to underestimate standard errors, and consequently it leads to overstate statistical significance (Moulton, 1986). A panel data structure necessitates the clustering correlation as well Arrelano, 1987; Liang and Zeger, 1988). An advantage of seeing the estimation of $\mu$ as m-estimation is 
the extension to the cluster robust estimator is straightforward by following Cameron et al. (2011), which even makes it possible to control for multiway clustering. For example, suppose that $G$ denotes the number of clusters, and there are $N_{g}$ observations within each cluster: $N=\sum_{g}^{G} N_{g}$. Then, the one-way clustering robust variance estimator is

$$
\begin{aligned}
\widehat{V}_{c}(\widehat{\mu})= & N^{-1} \sum_{g=1}^{G}\left(\sum_{i=1}^{N_{g}} \widehat{h}_{\mu i}\right)\left(\sum_{i=1}^{N_{g}} \widehat{h}_{\mu i}\right){ }^{\prime}+ \\
& \left(N^{-1} \sum_{g=1}^{G} \sum_{i=1}^{N_{g}} \partial h_{\mu i} /\left.\partial \theta^{\prime}\right|_{\theta=\widehat{\theta}}\right) \widehat{V}_{c}(\widehat{\theta})\left(N^{-1} \sum_{g=1}^{G} \sum_{i=1}^{N_{g}} \partial h_{\mu i} /\left.\partial \theta^{\prime}\right|_{\theta=\widehat{\theta}}\right)
\end{aligned}
$$

where $\widehat{V}_{c}(\widehat{\theta})$ is the cluster robust variance of $\theta: 5$

\subsection{Alternative Estimation}

This subsection discusses an alternative to $\mu$ and its asymptotic variance. As mentioned previously, Jann (2008) derives the standard errors of the linear decomposition allowing stochastic regressors. The derivation is based on the fact that the estimation of $\mu_{j k}$ is the product of two vectors for the linear decomposition. Suppose $\bar{x}_{k}$ is the vector of sample means of the regressors of the group of $d_{i}=k$, that is, an estimate of $E\left[x_{i} \mid d_{i}=k\right]$, and $\widehat{\beta}_{j}$ is the estimated coefficient vector of the group of $d_{i}=j$. Then, $\widehat{\mu}_{j k}=\bar{x}_{k}^{\prime} \widehat{\beta}_{j}$, and the variance of $\widehat{\mu}_{j k}$ is $\bar{x}_{k}{ }^{\prime} V\left(\widehat{\beta}_{k}\right) \bar{x}_{k}+\widehat{\beta}_{j}{ }^{\prime} V\left(\bar{x}_{k}\right) \widehat{\beta}_{j}+\operatorname{trace}\left(V\left(\bar{x}_{k}\right) V\left(\widehat{\beta}_{j}\right)\right)$ although the last term asymptotically vanishes (Jann, 2008). However, this derivation cannot be extended to nonlinear models since $\widehat{\mu}_{j k}$ is not the function of the product of the two vectors, $\bar{w}_{i}$ and $\widehat{\theta}_{j}$, but the average of $F\left(w_{i} ; \widehat{\theta}_{j}\right)$ over the sample with $d_{i}=k$.

${ }^{5}$ As a finite-sample adjustment, we multiply $\widehat{V}_{c}(\widehat{\mu})$ by $G /(G-1)$ in estimating the variances in the following sections. 
To explore more, define

$$
\widetilde{\mu}=\left(\begin{array}{c}
\widetilde{\mu}_{11} \\
\widetilde{\mu}_{01} \\
\widetilde{\mu}_{10} \\
\widetilde{\mu}_{00}
\end{array}\right)=\left(\begin{array}{c}
F\left(\mu_{w_{1}} ; \theta_{1}\right) \\
F\left(\mu_{w_{1}} ; \theta_{0}\right) \\
F\left(\mu_{w_{0}} ; \theta_{1}\right) \\
F\left(\mu_{w_{0}} ; \theta_{0}\right),
\end{array}\right)
$$

where $\mu_{w_{j}}=E\left[w_{i} \mid d_{i}=j\right]$. Obviously, $\widetilde{\mu}$ is not identical to $\mu$ unless $F(\cdot)$ is a linear function. We estimate $\widetilde{\mu}_{j k}$ by $F\left(\bar{w}_{k} ; \widehat{\theta}_{j}\right)$. As $\widehat{\theta}$ and $\bar{w}=\left(\bar{w}_{1}^{\prime}, \bar{w}_{0}{ }^{\prime}\right)^{\prime}$ are asymptotically independent, the asymptotic variance of $\widehat{\widetilde{\mu}}$ is

$$
V(\widehat{\widetilde{\mu}})=\widetilde{G}_{\widetilde{\mu} \mu_{w}} V(\bar{w}) \widetilde{G}_{\widetilde{\mu} \mu_{w}}{ }^{\prime}+\widetilde{G}_{\widetilde{\mu} \theta} V(\widehat{\theta}) \widetilde{G}_{\widetilde{\mu} \theta}{ }^{\prime}
$$

where $\widetilde{G}_{\widetilde{\mu} \mu_{w}}=\partial \widetilde{\mu} / \partial \mu_{w}$ and $\widetilde{G}_{\widetilde{\mu} \theta}=\partial \widetilde{\mu} / \partial \theta$. This expression has parallel structure to $V(\widehat{\mu})$. The first term arises from the fact the regressors are stochastic while the second term expresses the variability that comes from $\widehat{\theta}$. However, for the nonlinear models, the asymptotic distributions of $\widehat{\mu}$ and $\widehat{\widetilde{\mu}}$ are not equivalent. Thus, it is not appropriate to use $V(\widehat{\widetilde{\mu}})$ to make an inference on $\mu$. For comparison, we estimate $V(\widehat{\widetilde{\mu}})$ in addition to $V(\widehat{\mu})$ in the Monte Carlo simulations and the real-data application in the following sections.

\section{Monte Carlo Simulation}

In this section we conduct the Monte Carlo simulation study to see the performance of the variance estimators discussed in the preceding sections. Besides the linear decomposition based on OLS, we consider several nonlinear models: Specifically, probit and logit for a binary outcome, Tobit for a censored outcome, and Poisson and Negative Binomial (NB) for a count data outcome. For the OLS, probit, and Tobit models, the data generating process 
$(\mathrm{DGP})$ is $y_{j i}^{*}=\beta_{0 j}+\beta_{1 j} x_{1 i}+\beta_{2 j} x_{2 i}+\varepsilon_{j i}$, where $\varepsilon_{j i} \sim \mathcal{N}(0,1)$. Then, $y_{j i}=y_{j i}^{*}$ for the OLS, $y_{j i}=1\left(y_{j i}^{*}>0\right)$ for probit, and $y_{j i}=y_{j i}^{*} \times 1\left(y_{j i}^{*}>0\right)$ for Tobit, where $1(\cdot)$ is an indicator function. For the logit model, $y_{j i}=1\left(\beta_{0 j}+\beta_{1 j} x_{1 i}+\beta_{2 j} x_{2 i}+\varepsilon_{j i}>0\right)$, where $\varepsilon_{j i}$ follows the logistic distribution. For the Poisson and Negative Binomial models, $y_{j i}$ is generated to have a mean equal to $\exp \left(\beta_{0 j}+\beta_{1 j} x_{1 i}+\beta_{2 j} x_{2 i}\right)$. For the Negative Binomial model, the dispersion parameter $\alpha_{j}$ is set to 0.5 . We set the coefficients and DGPs of regressors the same for each group $d_{i}: \beta_{0 j}=0.5, \beta_{1 j}=1$, and $\beta_{2 j}=-0.5$ for $j=0,1$, and two regressors are distributed as $x_{1 i} \sim \mathcal{N}(0,1)$ and $x_{2 i} \sim \chi_{10}^{2}$, the latter of which is subtracted by 10 and divided by $\sqrt{20}$ to have mean 0 and variance 1 . Hence, the true values of coefficient and endowment effects are zero for all experiments. This is for a practical reason that we cannot compute the true values analytically unless the DGPs are the same across groups for the nonlinear models.

We consider the sample sizes $N=1,000$ and 5,000. Instead of fixing the size of each group, we allow it to vary at each replication. Specifically, the value of $d_{i}$ is assigned as $d_{i}=1\left(u_{i}+\nu_{i}>d^{*}\right)$, where $u_{i} \sim$ uniform $(0,1)$ and $\nu_{i} \sim \mathcal{N}(0,0.01)$. The latter adds slightly more variability to $d_{i}$. The threshold value $d^{*}$ controls the proportional size of each group. That is, $d^{*}$ and $\left(1-d^{*}\right)$ are the probabilities of $d_{i}=0$ and $d_{i}=1$, respectively. We consider five values of $d^{*}: d^{*} \in\{0.1,0.2,0.3,0.4,0.5\}$. We run 10,000 replications for each setting.

Table 1 reports the benchmark results when $d^{*}=0.5$. Columns (1) and (2) report the standard deviations of Monte Carlo replicates of decomposition effects based on $\mu$ and $\widetilde{\mu}$, respectively. As expected, the sampling distributions differ between $\mu$ and $\widetilde{\mu}$ for the nonlinear models. Especially, the endowment effects of Poisson and NB models show large differences. The endowment effects based on $\mu$, i.e., $R_{e} \mu$, exhibit twice as large variation as that on $\widetilde{\mu}$, i.e., $R_{e} \widetilde{\mu}$, and these differences do not vanish even with larger samples.

Columns (3)-(5) are the averages of estimated standard errors over 10,000 replicates. By comparing column (1) and column (3), we can see that the averages of our proposed standard errors that account for the variability of regressors are very close to the Monte Carlo 
Table 1: The Monte Carlo Results: Benchmark

\begin{tabular}{|c|c|c|c|c|c|c|c|c|c|}
\hline & & \multicolumn{2}{|c|}{ Std. Dev. ${ }^{\mathrm{a}}$} & \multicolumn{3}{|c|}{ Average of Std. Err. ${ }^{b}$} & \multicolumn{3}{|c|}{ Rejection Probability ${ }^{\mathrm{c}}$} \\
\hline & & $\mu$ & $\widetilde{\mu}$ & s.e. $(\widehat{\mu})$ & s.e. $(\widehat{\mu})_{d}$ & s.e. $(\widehat{\widetilde{\mu}})$ & s.e. $(\widehat{\mu})$ & s.e. $(\widehat{\mu})_{d}$ & s.e. $(\widehat{\widetilde{\mu}})$ \\
\hline & & (1) & (2) & $(3)$ & $(4)$ & (5) & (6) & (7) & (8) \\
\hline \multicolumn{10}{|c|}{$N=1,000$} \\
\hline OLS & $\begin{array}{l}\mathrm{E} \\
\mathrm{C}\end{array}$ & $\begin{array}{l}0.0707 \\
0.0630\end{array}$ & $\begin{array}{l}0.0707 \\
0.0630\end{array}$ & $\begin{array}{l}0.0708 \\
0.0633\end{array}$ & $\begin{array}{l}0.0035 \\
0.0632\end{array}$ & $\begin{array}{l}0.0708 \\
0.0633\end{array}$ & $\begin{array}{l}0.0491 \\
0.0497\end{array}$ & $\begin{array}{l}0.9492 \\
0.0501\end{array}$ & $\begin{array}{l}0.0491 \\
0.0497\end{array}$ \\
\hline Probit & $\begin{array}{l}\mathrm{E} \\
\mathrm{C}\end{array}$ & $\begin{array}{l}0.0195 \\
0.0248\end{array}$ & $\begin{array}{l}0.0287 \\
0.0375\end{array}$ & $\begin{array}{l}0.0195 \\
0.0249\end{array}$ & $\begin{array}{l}0.0014 \\
0.0249\end{array}$ & $\begin{array}{l}0.0286 \\
0.0376\end{array}$ & $\begin{array}{l}0.0509 \\
0.0506\end{array}$ & $\begin{array}{l}0.8988 \\
0.0513\end{array}$ & $\begin{array}{l}0.0040 \\
0.0024\end{array}$ \\
\hline Logit & $\begin{array}{l}\mathrm{E} \\
\mathrm{C}\end{array}$ & $\begin{array}{l}0.0145 \\
0.0283\end{array}$ & $\begin{array}{l}0.0182 \\
0.0357\end{array}$ & $\begin{array}{l}0.0144 \\
0.0283\end{array}$ & $\begin{array}{l}0.0016 \\
0.0282\end{array}$ & $\begin{array}{l}0.0180 \\
0.0357\end{array}$ & $\begin{array}{l}0.0497 \\
0.0520\end{array}$ & $\begin{array}{l}0.8683 \\
0.0523\end{array}$ & $\begin{array}{l}0.0135 \\
0.0153\end{array}$ \\
\hline Tobit & $\begin{array}{l}\mathrm{E} \\
\mathrm{C}\end{array}$ & $\begin{array}{l}0.0381 \\
0.0394\end{array}$ & $\begin{array}{l}0.0354 \\
0.0407\end{array}$ & $\begin{array}{l}0.0380 \\
0.0407\end{array}$ & $\begin{array}{l}0.0026 \\
0.0406\end{array}$ & $\begin{array}{l}0.0355 \\
0.0459\end{array}$ & $\begin{array}{l}0.0504 \\
0.0448\end{array}$ & $\begin{array}{l}0.9323 \\
0.0456\end{array}$ & $\begin{array}{l}0.0690 \\
0.0222\end{array}$ \\
\hline Poisson & $\begin{array}{l}\mathrm{E} \\
\mathrm{C}\end{array}$ & $\begin{array}{l}0.1734 \\
0.0864\end{array}$ & $\begin{array}{l}0.0707 \\
0.0703\end{array}$ & $\begin{array}{l}0.1719 \\
0.0866\end{array}$ & $\begin{array}{l}0.0108 \\
0.0856\end{array}$ & $\begin{array}{l}0.0708 \\
0.0701\end{array}$ & $\begin{array}{l}0.0439 \\
0.0497\end{array}$ & $\begin{array}{l}0.9411 \\
0.0531\end{array}$ & $\begin{array}{l}0.4201 \\
0.1101\end{array}$ \\
\hline NB & $\begin{array}{l}\mathrm{E} \\
\mathrm{C}\end{array}$ & $\begin{array}{l}0.1762 \\
0.1599\end{array}$ & $\begin{array}{l}0.0707 \\
0.0892\end{array}$ & $\begin{array}{l}0.1744 \\
0.1594\end{array}$ & $\begin{array}{l}0.0213 \\
0.1575\end{array}$ & $\begin{array}{l}0.0708 \\
0.0880\end{array}$ & $\begin{array}{l}0.0397 \\
0.0449\end{array}$ & $\begin{array}{l}0.9059 \\
0.0522\end{array}$ & $\begin{array}{l}0.4239 \\
0.2719\end{array}$ \\
\hline$N=$ & & & & & & & & & \\
\hline OLS & $\begin{array}{l}\mathrm{E} \\
\mathrm{C}\end{array}$ & $\begin{array}{l}0.0315 \\
0.0283\end{array}$ & $\begin{array}{l}0.0315 \\
0.0283\end{array}$ & $\begin{array}{l}0.0316 \\
0.0283\end{array}$ & $\begin{array}{l}0.0007 \\
0.0283\end{array}$ & $\begin{array}{l}0.0316 \\
0.0283\end{array}$ & $\begin{array}{l}0.0484 \\
0.0504\end{array}$ & $\begin{array}{l}0.9783 \\
0.0504\end{array}$ & $\begin{array}{l}0.0484 \\
0.0504\end{array}$ \\
\hline Probit & $\begin{array}{l}\mathrm{E} \\
\mathrm{C}\end{array}$ & $\begin{array}{l}0.0086 \\
0.0111\end{array}$ & $\begin{array}{l}0.0126 \\
0.0167\end{array}$ & $\begin{array}{l}0.0087 \\
0.0111\end{array}$ & $\begin{array}{l}0.0003 \\
0.0111\end{array}$ & $\begin{array}{l}0.0126 \\
0.0167\end{array}$ & $\begin{array}{l}0.0491 \\
0.0498\end{array}$ & $\begin{array}{l}0.9511 \\
0.0499\end{array}$ & $\begin{array}{l}0.0038 \\
0.0031\end{array}$ \\
\hline Logit & $\begin{array}{l}\mathrm{E} \\
\mathrm{C}\end{array}$ & $\begin{array}{l}0.0064 \\
0.0127\end{array}$ & $\begin{array}{l}0.0080 \\
0.0159\end{array}$ & $\begin{array}{l}0.0064 \\
0.0126\end{array}$ & $\begin{array}{l}0.0003 \\
0.0126\end{array}$ & $\begin{array}{l}0.0079 \\
0.0159\end{array}$ & $\begin{array}{l}0.0490 \\
0.0487\end{array}$ & $\begin{array}{l}0.9471 \\
0.0488\end{array}$ & $\begin{array}{l}0.0157 \\
0.0158\end{array}$ \\
\hline Tobit & $\begin{array}{l}\mathrm{E} \\
\mathrm{C}\end{array}$ & $\begin{array}{l}0.0169 \\
0.0176\end{array}$ & $\begin{array}{l}0.0157 \\
0.0181\end{array}$ & $\begin{array}{l}0.0169 \\
0.0182\end{array}$ & $\begin{array}{l}0.0005 \\
0.0182\end{array}$ & $\begin{array}{l}0.0158 \\
0.0206\end{array}$ & $\begin{array}{l}0.0493 \\
0.0416\end{array}$ & $\begin{array}{l}0.9705 \\
0.0419\end{array}$ & $\begin{array}{l}0.0665 \\
0.0218\end{array}$ \\
\hline Poisson & $\begin{array}{l}\mathrm{E} \\
\mathrm{C}\end{array}$ & $\begin{array}{l}0.0774 \\
0.0385\end{array}$ & $\begin{array}{l}0.0313 \\
0.0316\end{array}$ & $\begin{array}{l}0.0773 \\
0.0384\end{array}$ & $\begin{array}{l}0.0022 \\
0.0383\end{array}$ & $\begin{array}{l}0.0316 \\
0.0313\end{array}$ & $\begin{array}{l}0.0509 \\
0.0491\end{array}$ & $\begin{array}{l}0.9705 \\
0.0496\end{array}$ & $\begin{array}{l}0.4182 \\
0.1123\end{array}$ \\
\hline NB & $\begin{array}{l}\mathrm{E} \\
\mathrm{C}\end{array}$ & $\begin{array}{l}0.0780 \\
0.0705\end{array}$ & $\begin{array}{l}0.0315 \\
0.0395 \\
\end{array}$ & $\begin{array}{l}0.0776 \\
0.0706 \\
\end{array}$ & $\begin{array}{l}0.0044 \\
0.0704\end{array}$ & $\begin{array}{l}0.0316 \\
0.0394 \\
\end{array}$ & $\begin{array}{l}0.0490 \\
0.0471\end{array}$ & $\begin{array}{l}0.9581 \\
0.0483\end{array}$ & $\begin{array}{l}0.4217 \\
0.2712 \\
\end{array}$ \\
\hline
\end{tabular}

a The standard deviations of 10,000 replicates. Endowment (E) and Coefficient (C) effects are computed with $d_{i}=1$ as a reference group. That is, $\mathrm{E}=R_{e} \mu$ and $\mathrm{C}=R_{c} \mu$ (column (1)) and $\mathrm{E}=R_{e} \widetilde{\mu}$ and $\mathrm{C}=R_{c} \widetilde{\mu}$ (column (2)), where $R_{e}=(0,1,0,-1)$ and $R_{c}=(1,-1,0,0)$. The results with $d_{i}=0$ as a reference group are similar and omitted here. The results are available upon request.

b The averages of 10,000 replicates of estimated standard errors. The standard errors are s.e. $(\widehat{\mu})=$ $\sqrt{R . \widehat{V}(\widehat{\mu}) R^{\prime} / N}$, s.e. $(\widehat{\mu})_{d}=\sqrt{R \cdot\left(\widehat{G}_{\mu \theta} \widehat{V}(\widehat{\theta}) \widehat{G}_{\mu \theta^{\prime}}\right) R^{\prime} / N}$, and s.e. $(\widehat{\widetilde{\mu}})=\sqrt{R \cdot \widehat{V}(\widehat{\widetilde{\mu}}) R .^{\prime} / N}$ with $R .=R_{e}$ or $R_{c}$ correspondingly.

c The relative frequencies that the null hypothesis $R . \mu=0$ is rejected at the $5 \%$ significance level. The test statistics are calculated with the corresponding standard errors. 
standard deviations. On the other hand, the delta method standard errors, which is shown in column (4), of the endowment effect (E) are considerably smaller than the Monte Carlo standard deviations as a result of not considering the variability of regressors. However, note that the delta method standard errors of the coefficient effect $(\mathrm{C})$ are comparable with the Monte Carlo standard deviations. To see why, consider the OLS model. As clear from equation (4), the difference between our proposed variance estimator and the delta method variance estimator arises due to $S_{\mu \mu}$. It can be shown that for the endowment effect, $R_{e} S_{\mu \mu} R_{e}{ }^{\prime}=\beta_{0}{ }^{\prime} \operatorname{Var}\left(x_{1}\right) \beta_{0}+\beta_{0}{ }^{\prime} \operatorname{Var}\left(x_{0}\right) \beta_{0}$, where $\operatorname{Var}\left(x_{j}\right)$ is the variance of $x_{i}$ conditional on $d_{i}=j$. Since these two terms are positive, our proposed variance will always be larger than the delta method variance. On the other hand, for the coefficient effect, $R_{c} S_{\mu \mu} R_{c}{ }^{\prime}=$ $\beta_{1}{ }^{\prime} \operatorname{Var}\left(x_{1}\right) \beta_{1}+\beta_{0}{ }^{\prime} \operatorname{Var}\left(x_{1}\right) \beta_{0}-2 \beta_{1}{ }^{\prime} \operatorname{Var}\left(x_{1}\right) \beta_{0}$. When $\beta_{1}=\beta_{0}$, the last term completely cancel out the first two terms. This implies that when $\widehat{\beta}_{1}$ and $\widehat{\beta}_{0}$ are close to each other, our proposed variance estimator will also get close to the delta method variance estimator. The same argument applies to the nonlinear models.

Columns (6)-(8) report the relative frequencies of the rejection of the null hypothesis that $\mathrm{E}=R_{e} \mu=0$ or $\mathrm{C}=R_{c} \mu=0$ at the $5 \%$ significance level. Since the true values of $\mathrm{E}$ and $\mathrm{C}$ are zero in our setting, the relative frequencies measure a size of the test. As column (6) shows, there are little size distortions when the test statistics are computed with our proposed variance estimator except for the tests for the Poisson and NB models, which are under-sized when the sample size is small. Column (7) shows that the delta method variance leads to severe size distortions when the endowment effects are examined. Column (8) shows that computing the test statistics based on $V(\widetilde{\mu})$ results in severe size distortions. It is because that the variance $V(\widetilde{\mu})$ does not represent the variability of $\mu$ properly $]^{6}$

Table 2 reports the rejection probabilities that based on $\widehat{V}(\widehat{\mu})$ for different values of $d^{*}$.

\footnotetext{
${ }^{6}$ Although not reported here, when the null hypothesis is $R_{e} \widetilde{\mu}=0$ or $R_{c} \widetilde{\mu}=0$, the tests based on $V(\widetilde{\mu})$ perform well.
} 
Table 2: Rejection Probabilities with Different Threshold Value $d^{*}$

\begin{tabular}{|c|c|c|c|c|c|c|}
\hline & & \multicolumn{5}{|c|}{ Threshold Value $d^{*}$} \\
\hline & & 0.5 & 0.4 & 0.3 & 0.2 & 0.1 \\
\hline & & (1) & $(2)$ & (3) & (4) & (5) \\
\hline \multicolumn{7}{|c|}{$N=1,000$} \\
\hline OLS & $\begin{array}{l}\mathrm{E} \\
\mathrm{C}\end{array}$ & $\begin{array}{l}0.0491 \\
0.0497\end{array}$ & $\begin{array}{l}0.0462 \\
0.0489\end{array}$ & $\begin{array}{l}0.0500 \\
0.0518\end{array}$ & $\begin{array}{l}0.0492 \\
0.0524\end{array}$ & $\begin{array}{l}0.0507 \\
0.0524\end{array}$ \\
\hline Probit & $\begin{array}{l}\mathrm{E} \\
\mathrm{C}\end{array}$ & $\begin{array}{l}0.0509 \\
0.0506\end{array}$ & $\begin{array}{l}0.0465 \\
0.0504\end{array}$ & $\begin{array}{l}0.0505 \\
0.0526\end{array}$ & $\begin{array}{l}0.0504 \\
0.0527\end{array}$ & $\begin{array}{l}0.0529 \\
0.0545\end{array}$ \\
\hline Logit & $\begin{array}{l}\mathrm{E} \\
\mathrm{C}\end{array}$ & $\begin{array}{l}0.0497 \\
0.0520\end{array}$ & $\begin{array}{l}0.0484 \\
0.0516\end{array}$ & $\begin{array}{l}0.0456 \\
0.0511\end{array}$ & $\begin{array}{l}0.0492 \\
0.0502\end{array}$ & $\begin{array}{l}0.0499 \\
0.0514\end{array}$ \\
\hline Tobit & $\begin{array}{l}\mathrm{E} \\
\mathrm{C}\end{array}$ & $\begin{array}{l}0.0504 \\
0.0448\end{array}$ & $\begin{array}{l}0.0490 \\
0.0428\end{array}$ & $\begin{array}{l}0.0507 \\
0.0409\end{array}$ & $\begin{array}{l}0.0514 \\
0.0420\end{array}$ & $\begin{array}{l}0.0557 \\
0.0459\end{array}$ \\
\hline Poisson & $\begin{array}{l}\mathrm{E} \\
\mathrm{C}\end{array}$ & $\begin{array}{l}0.0439 \\
0.0497\end{array}$ & $\begin{array}{l}0.0471 \\
0.0483\end{array}$ & $\begin{array}{l}0.0518 \\
0.0487\end{array}$ & $\begin{array}{l}0.0609 \\
0.0482\end{array}$ & $\begin{array}{l}0.0753 \\
0.0533\end{array}$ \\
\hline NB & $\begin{array}{l}\mathrm{E} \\
\mathrm{C}\end{array}$ & $\begin{array}{l}0.0397 \\
0.0449\end{array}$ & $\begin{array}{l}0.0443 \\
0.0441\end{array}$ & $\begin{array}{l}0.0459 \\
0.0454\end{array}$ & $\begin{array}{l}0.0584 \\
0.0447\end{array}$ & $\begin{array}{l}0.0734 \\
0.0461\end{array}$ \\
\hline$N=5$, & & & & & & \\
\hline OLS & $\begin{array}{l}\mathrm{E} \\
\mathrm{C}\end{array}$ & $\begin{array}{l}0.0484 \\
0.0504\end{array}$ & $\begin{array}{l}0.0513 \\
0.0512\end{array}$ & $\begin{array}{l}0.0494 \\
0.0502\end{array}$ & $\begin{array}{l}0.0496 \\
0.0499\end{array}$ & $\begin{array}{l}0.0511 \\
0.0524\end{array}$ \\
\hline Probit & $\begin{array}{l}\mathrm{E} \\
\mathrm{C}\end{array}$ & $\begin{array}{l}0.0491 \\
0.0498\end{array}$ & $\begin{array}{l}0.0513 \\
0.0491\end{array}$ & $\begin{array}{l}0.0495 \\
0.0490\end{array}$ & $\begin{array}{l}0.0485 \\
0.0493\end{array}$ & $\begin{array}{l}0.0495 \\
0.0505\end{array}$ \\
\hline Logit & $\begin{array}{l}\mathrm{E} \\
\mathrm{C}\end{array}$ & $\begin{array}{l}0.0490 \\
0.0487\end{array}$ & $\begin{array}{l}0.0528 \\
0.0496\end{array}$ & $\begin{array}{l}0.0550 \\
0.0491\end{array}$ & $\begin{array}{l}0.0531 \\
0.0498\end{array}$ & $\begin{array}{l}0.0515 \\
0.0460\end{array}$ \\
\hline Tobit & $\begin{array}{l}\mathrm{E} \\
\mathrm{C}\end{array}$ & $\begin{array}{l}0.0493 \\
0.0416\end{array}$ & $\begin{array}{l}0.0512 \\
0.0451\end{array}$ & $\begin{array}{l}0.0499 \\
0.0465\end{array}$ & $\begin{array}{l}0.0533 \\
0.0457\end{array}$ & $\begin{array}{l}0.0483 \\
0.0481\end{array}$ \\
\hline Poisson & $\begin{array}{l}\mathrm{E} \\
\mathrm{C}\end{array}$ & $\begin{array}{l}0.0509 \\
0.0491\end{array}$ & $\begin{array}{l}0.0482 \\
0.0504\end{array}$ & $\begin{array}{l}0.0480 \\
0.0516\end{array}$ & $\begin{array}{l}0.0501 \\
0.0554\end{array}$ & $\begin{array}{l}0.0576 \\
0.0529\end{array}$ \\
\hline NB & $\begin{array}{l}\mathrm{E} \\
\mathrm{C}\end{array}$ & $\begin{array}{l}0.0490 \\
0.0471\end{array}$ & $\begin{array}{l}0.0464 \\
0.0485\end{array}$ & $\begin{array}{l}0.0498 \\
0.0471\end{array}$ & $\begin{array}{l}0.0526 \\
0.0494\end{array}$ & $\begin{array}{l}0.0567 \\
0.0474\end{array}$ \\
\hline
\end{tabular}

Note: See the notes in 1 .

As $d^{*}$ gets smaller and smaller, the sizes become more and more distorted, in particular, for the Poisson and NB models. The size distortions tend to be less severe when $N=5,000$ than when $N=1,000$.

In addition to the case where each observation is independent of one another, we also consider the case where observations are correlated with clusters. To do so, we restrict the regressor $x_{2}$ to vary only at a cluster level and add cluster-specific error components. More 
Table 3: The Monte Carlo Results: Clustering

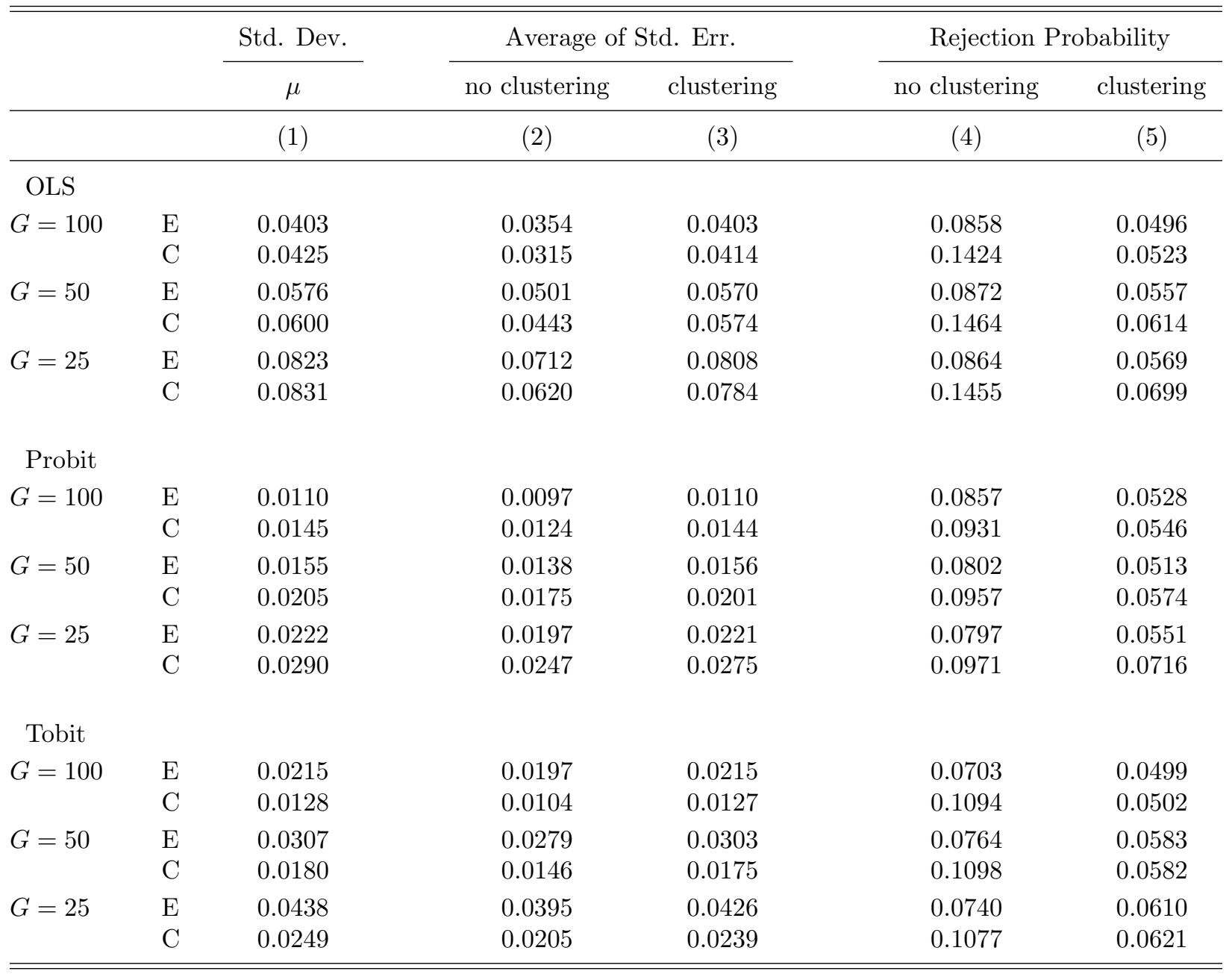

Note: See the notes in 1. This table report the results based on $\mu$.

specifically, we consider the following DGP: $y_{i}^{*}=\beta_{0}+\beta_{1} x_{1 i}+\beta_{2} x_{2 g}+\sqrt{0.5}\left(\varepsilon_{i}+\varepsilon_{g}\right)$, where $\varepsilon_{i} \sim \mathcal{N}(0,1)$ and $\varepsilon_{g} \sim \mathcal{N}(0,1)$ for $g=1, \ldots, G$. In this exercise, we consider only OLS, probit, and Tobit models. As before, $y_{j i}=y_{j i}^{*}$ for the OLS, $y_{j i}=1\left(y_{j i}^{*}>0\right)$ for probit, and $y_{j i}=y_{j i}^{*} \times 1\left(y_{j i}^{*}>0\right)$ for Tobit, and there is no difference in DGP by group. Besides, we also add the clustering correlation to the group assignment process: $d_{i}=1\left(u_{i}+\nu_{g}>d_{*}\right)$, where $\nu_{g} \sim \mathcal{N}(0,0.01)$, following Kline (2014). We set the number of clusters as $G=25,50$, and 100. There are 40 observations in each cluster. That is, $N_{g}=40$ and $N=40 \times G$.

Table 3 reports the results. As columns (2) and (4) show, the standard errors that 
ignore clustering underestimate the true variability of the decomposition effects and lead to over-rejection of the true null hypothesis. When the clustering correlation is taken into account, our proposed variance estimator is able to estimate the true variability. However, when the number of clusters is smaller, the cluster-robust variance estimator becomes biased downward. This result is consistent with the findings in the previous literature. It is because the cluster-robust variance builds on the assumption that $G$ goes to infinity. However, as the analytical form of the cluster-robust variance estimator is presented, it is feasible to correct bias by asymptotic refinement using the bootstrap method (Cameron et al., 2008).

\section{Real-Data Application}

This section illustrates a real-data application. The data set used for this application is from the RAND Health Insurance Experiment (HIE).77 We decompose the gender differences of various outcomes: an observation $i$ is female if $d_{i}=1$. Specifically, the outcomes of interest are annual individual health expenditures, a binary choice of whether the expenditure is positive, and the number of outpatient visits. The expenditures in logarithms given positive expenditures are decomposed by OLS, and the binary choice is decomposed by the probit and logit models. The Tobit model is also used for the annual expenditure (not in log) to capture zero expenditures. The number of outpatient visits is count data, and thus, we employ the Poisson and Negative Binomial (NB) model. Furthermore, we also consider the hurdle Poisson and NB models and zero-inflated Poisson and NB models since zero outpatient visits account for a considerable portion of the sample (around 31\%). For the process governing zero counts, we use the logit model with the same regressors as the process for positive counts. That is, $x_{i}=z_{i}$. We use the same regressors for all the outcomes. See Appendix $\mathrm{C}$ for the definitions and summary statistics of these variables.

7 The data extract is downloaded from http://cameron.econ.ucdavis.edu/mmabook/mmaprograms. html. 
Table 4: Real-Data Application: HIE data

\begin{tabular}{|c|c|c|c|c|c|c|c|c|}
\hline & & \multirow[b]{2}{*}{ Est. } & \multicolumn{4}{|c|}{ Benchmark $^{a}$} & \multicolumn{2}{|c|}{ Clustering $^{\mathrm{b}}$} \\
\hline & & & s.e. $(\widehat{\mu})$ & s.e. $(\widehat{\mu})_{d}$ & s.e. $(\widehat{\widetilde{\mu}})$ & s.e. $(\widehat{\mu})_{b}{ }^{\mathrm{c}}$ & s.e. $(\widehat{\mu})$ & s.e. $(\widehat{\mu})_{b}{ }^{\mathrm{c}}$ \\
\hline & & (1) & $(2)$ & (3) & (4) & (5) & (6) & (7) \\
\hline \multirow[t]{2}{*}{ OLS } & Endowment & 0.151 & 0.011 & 0.007 & 0.011 & 0.011 & 0.019 & 0.019 \\
\hline & Coefficient & 0.182 & 0.023 & 0.023 & 0.023 & 0.021 & 0.029 & 0.028 \\
\hline \multirow[t]{2}{*}{ Probit } & Endowment & 0.010 & 0.002 & 0.001 & 0.003 & 0.002 & 0.004 & 0.004 \\
\hline & Coefficient & 0.068 & 0.006 & 0.006 & 0.006 & 0.006 & 0.008 & 0.008 \\
\hline \multirow[t]{2}{*}{ Logit } & Endowment & 0.010 & 0.002 & 0.001 & 0.003 & 0.002 & 0.004 & 0.004 \\
\hline & Coefficient & 0.067 & 0.006 & 0.006 & 0.006 & 0.006 & 0.008 & 0.008 \\
\hline \multirow{2}{*}{ Tobit } & Endowment & 19.290 & 2.757 & 2.086 & 2.437 & 2.600 & 4.402 & 4.581 \\
\hline & Coefficient & 6.023 & 48.808 & 48.804 & 47.504 & 51.344 & 49.678 & 49.455 \\
\hline \multirow[t]{2}{*}{ Poisson } & Endowment & 0.271 & 0.032 & 0.025 & 0.025 & 0.034 & 0.055 & 0.057 \\
\hline & Coefficient & 0.559 & 0.060 & 0.060 & 0.057 & 0.062 & 0.091 & 0.091 \\
\hline \multirow[t]{2}{*}{ NB } & Endowment & 0.288 & 0.033 & 0.024 & 0.025 & 0.034 & 0.056 & 0.054 \\
\hline & Coefficient & 0.556 & 0.061 & 0.061 & 0.057 & 0.063 & 0.093 & 0.091 \\
\hline \multirow[t]{2}{*}{ ZIP } & Endowment & 0.286 & 0.032 & 0.025 & 0.022 & 0.034 & 0.055 & 0.057 \\
\hline & Coefficient & 0.544 & 0.060 & 0.060 & 0.073 & 0.062 & 0.091 & 0.090 \\
\hline \multirow[t]{2}{*}{ ZINB } & Endowment & 0.288 & 0.032 & 0.024 & 0.024 & 0.033 & 0.054 & 0.054 \\
\hline & Coefficient & 0.546 & 0.060 & 0.060 & 0.087 & 0.063 & 0.092 & 0.090 \\
\hline \multirow[t]{2}{*}{ HP } & Endowment & 0.275 & 0.031 & 0.024 & 0.024 & 0.033 & 0.053 & 0.055 \\
\hline & Coefficient & 0.533 & 0.056 & 0.055 & 0.054 & 0.058 & 0.085 & 0.084 \\
\hline \multirow[t]{2}{*}{ HNB } & Endowment & 0.280 & 0.031 & 0.023 & 0.025 & 0.033 & 0.053 & 0.054 \\
\hline & Coefficient & 0.541 & 0.061 & 0.060 & 0.061 & 0.062 & 0.092 & 0.090 \\
\hline
\end{tabular}

a The benchmark standard errors treat all observations as independent.

${ }^{\mathrm{b}}$ Clustering at an individual level. There are 5,908 unique individuals in the data.

c The bootstrap standard errors are based on 200 replications.

${ }^{\mathrm{d}}$ A sample drawn at each replication is at the cluster (individual) level.

In the benchmark computations of standard errors, we assume that each observation is independent of one another. Besides, as the data have a panel structure, that is, multiple observations per individual, we also compute the standard errors controlling for clustering at an individual level. In addition to the various ways of estimating standard errors discussed above, we also compute the bootstrap standard errors for comparison.

Table 4 summarizes the results. Our proposed standard errors and bootstrap standard errors are comparable in all the models, so are they even in controlling for clustering. This fact 
validates our proposed variance estimator since the bootstrap approach is widely accepted in the applied literature. Although the time elapsed to conduct the bootstrap resampling is not measured, it is quite time-consuming, especially, for highly nonlinear cases such as zero-inflated Poisson and NB models. Of course, the analytical standard errors are computationally less intensive. Computational easiness is valuable to applied researchers. However, as noted above, the bootstrap approach is still useful along with the analytical variance in order to obtain asymptotic refinement. As expected, the delta method approach underestimates the standard errors of the endowment effect compared to the proposed and bootstrap estimators by ignoring the variability of the regressors. We can also see that the standard errors based on $\widetilde{\mu}$ do not coincide with the bootstrap standard errors.

\section{Conclusion}

This paper derives the asymptotic variance of the decomposition effects that are applicable to both linear and nonlinear cases. Our proposed estimator is an useful alternative to the bootstrap approach, which is the mostly used variance estimator in the applied literature of the nonlinear decomposition. We confirm the validity of our proposed variance estimator with the Monte Carlo simulations and the real-data application.

Our derivation of the asymptotic variance is in general settings, employing the framework of m-estimation. It makes it easy to extend the variance estimator to control for clustering correlation. our approach is also straightforward for further extensions. This section briefly mentions to several possible extensions.

First, we illustrate the decomposition using OLS and MLE since the literature has exclusively used these estimation methods. Our approach is clearly applicable to a nonlinear least squares model since it is one of m-estimators. It is also possible to extend to the decomposition based on generalized method of moments (GMM). Therefore, we are able to accommodate a variety of models. 
Second, the decomposition may have additional terms besides the endowment and coefficient effects described in the paper. For example, the "threefold" decomposition (Daymont and Andrisani, 1984) is often applied. In this case, the additional term is simply a combination of the elements of $\mu$ like the other two effects, and therefore, it is possible to estimate the variance in the same way as other two effects by setting $R$ properly. Also, the decomposition may also involve the $F(\cdot)$ evaluated with the parameters other than $\theta_{1}$ or $\theta_{0}$. For example, the parameters are estimated from a pooled sample or a weighted average of $\theta_{1}$ and $\theta_{0}$. We are able to apply the proposed approach by modifying the moment conditions at the first step and/or the second step.

Third, while the previous sections cover aggregate decompositions, the decomposition analysis often determines the contribution of each regressor to the endowment and coefficient effects (the "detailed" decomposition). Because of its linearity, the estimation of the detailed decomposition and its variance is straightforward for the OLS decomposition. We can simply divide the conditional expectations in (2) into the contribution of each regressor. For the nonlinear decomposition, there is no unified approach for the detailed decomposition 8 However, in principle, we can modify our approach so that we can estimate the asymptotic variance of the detailed decomposition for the nonlinear models.

The capability of these extensions values our proposed variance estimator further.

\section{Acknowledgment}

The author thanks Wim Vijverberg for his helpful comments.

\footnotetext{
${ }^{8}$ See, for example, Yun (2004) and Fairle (2006).
} 


\section{References}

Arrelano, M., 1987. Computing robust standard errors for within-group estimators. Oxford Bulletin of Economics and Statistics 49 (4), 431-434.

Bauer, T., Ghlmann, S., Sinning, M., 2007. Gender differences in smoking behavior. Health Economics 16 (9), 895-909.

Bauer, T., Sinning, M., 2008. An extension of the Blinder-Oaxaca decomposition to nonlinear models. Advances in Statistical Analysis 92 (2), 197-206.

Bauer, T., Sinning, M., 2010. Blinder-Oaxaca decomposition for tobit models. Applied Economics 42 (12), 1569-1575.

Blinder, A. S., 1973. Wage discrimination: Reduced form and structural estimates. The Journal of Human Resources 8 (4), 436-455.

Cameron, A., Trivedi, P., 2005. Microeconometrics: Methods and Applications. Cambridge University Press.

Cameron, A. C., Gelbach, J. B., Miller, D. L., 2008. Bootstrap-based improvements for inference with clustered errors. The Review of Economics and Statistics 90 (3), 414-427.

Cameron, A. C., Gelbach, J. B., Miller, D. L., 2011. Robust inference with multiway clustering. Journal of Business \& Economic Statistics 29 (2), 238-249.

Daymont, T. N., Andrisani, P. J., 1984. Job preferences, college major, and the gender gap in earning. Journal of Human Resources 19 (3), 408 - 428.

Fairle, R. W., 2006. An extension of the Blinder-Oaxaca decomposition technique to logit and probit models. Journal of Economic and Social Measurement 30 (4), 305-316. 
Fortin, N., Lemieux, T., Firpo, S., 2011. Chapter 1 - Decomposition Methods in Economics. Vol. 4, Part A of Handbook of Labor Economics. Elsevier, pp. 1 - 102.

Horowitz, J. L., 2001. The Bootstrap. Vol. V. Elsevier Science B.V., Ch. 52, pp. 3159-3228.

Jann, B., 2008. The Blinder-Oaxaca decomposition for linear regression models. The Stata Journal 8 (4), 453-479.

Kline, P., 2011. Oaxaca-Blinder as a reweighting estimator. The American Economic Review $101(3), 532-537$.

Kline, P., 2014. A note on variance estimation for the Oaxaca estimator of average treatment effects. Economics Letters 122 (3), 428 - 431.

Liang, K.-Y., Zeger, S. L., 1988. Longitudianl data analysis using generalized linear models. Biometrika 73 (1), 13-22.

Moulton, B. R., 1986. Random group effects and the precision of regression estimates. Journal of Econometrics 32 (3), 385-397.

Murphy, K. M., Topel, R. H., 1985. Estimation and inference in two-step econometric models. Journal of Business \& Economic Statistics 3 (4), 370-379.

Newey, W. K., 1984. A method of moments interpretation of sequential estimators. Economics Letters 14 (23), $201-206$.

Newey, W. K., McFadden, D., 1994. Large Sample Estimation and Hypothesis Testing. Vol. IV. Elsevier Science B.V., Ch. 36, pp. 2111-2245.

Oaxaca, R. L., 1973. Male-female wage differentials in urban labor markets. International Economic Review 14 (3), 693-709. 
Oaxaca, R. L., Ransom, M. R., 1998. Calculation of approximate variances for wage decomposition differentials. Journal of Economic and Social Measurement 24 (1), 55 - 61 .

Pagan, A., 1986. Two stage and related estimators and their applications. Review of Economic Studies $53(4), 517-538$.

Yun, M.-S., 2004. Decomposing differences in the first moment. Economics Letters 82 (2), $275-280$. 


\section{Appendices}

\section{A Proof of Proposition 1}

The derivation of asymptotic variance of $\widehat{\mu}$ is based on the sequential two-step estimation by Newey (1984). Murphy and Topel (1985) and Pagan (1986) also derive similar results, and Newey and McFadden (1994) and Cameron and Trivedi (2005) illustrate the derivation in a clear fashion. Let $\delta=\left(\theta^{\prime}, \mu^{\prime}\right)^{\prime}$. Then, $\delta$ can be estimated by solving the equations (3) and (3.1) simultaneously. The consistency of $\delta$ requires the population moment condition that $E\left(h_{\theta i}(\theta)^{\prime}, h_{\mu i}(\mu, \theta)\right)^{\prime}=0$. Under the regular conditions, the asymptotic distribution is

$$
\sqrt{N}(\widehat{\delta}-\delta) \stackrel{d}{\rightarrow} \mathcal{N}\left(0, G^{-1} S\left(G^{-1}\right)^{\prime}\right),
$$

where

$$
G=\lim N^{-1} \sum_{i=1}^{N} E\left(\begin{array}{cc}
\partial h_{\theta i}(\theta) / \partial \theta^{\prime} & \partial h_{\theta i}(\theta) / \partial \mu^{\prime} \\
\partial h_{\mu i}(\mu, \theta) / \partial \theta^{\prime} & \partial h_{\mu i}(\mu, \theta) / \partial \mu^{\prime}
\end{array}\right)=\left(\begin{array}{cc}
G_{\theta \theta} & G_{\theta \mu} \\
G_{\mu \theta} & G_{\theta \theta}
\end{array}\right)
$$

and

$$
S=\lim N^{-1} \sum_{i=1}^{N} E\left(\begin{array}{cc}
h_{\theta i}(\theta) h_{\theta i}(\theta)^{\prime} & h_{\theta i}(\theta) h_{\mu i}(\theta)^{\prime} \\
h_{\mu i}(\mu, \theta) h_{\theta i}(\theta)^{\prime} & h_{\mu i}(\mu, \theta) h_{\mu i}(\mu, \theta)^{\prime}
\end{array}\right)=\left(\begin{array}{cc}
S_{\theta \theta} & S_{\theta \mu} \\
S_{\mu \theta} & S_{\mu \mu}
\end{array}\right)
$$

Since $E\left[\partial h_{\theta i}(\theta) / \partial \mu^{\prime}\right]=G_{\theta \mu}=0$, the inverse of $G$ is

$$
G^{-1}=\left(\begin{array}{cc}
G_{\theta \theta}^{-1} & 0 \\
-G_{\mu \mu}^{-1} G_{\mu \theta} G_{\theta \theta} & G_{\mu \mu}^{-1}
\end{array}\right)
$$


Therefore, we can obtain the asymptotic variances of $\widehat{\theta}$ and $\widehat{\mu}$ :

$$
V(\widehat{\theta})=G_{\theta \theta}^{-1} S_{\theta \theta} G_{\theta \theta}^{-1}
$$

and

$$
V(\widehat{\mu})=G_{\mu \mu}^{-1}\left\{S_{\mu \mu}+G_{\mu \theta} G_{\theta \theta}^{-1} S_{\theta \theta} G_{\theta \theta}^{-1} G_{\mu \theta}{ }^{\prime}-G_{\mu \theta} G_{\theta \theta}^{-1} S_{\theta \mu}-S_{\mu \theta} G_{\theta \theta}^{-1} G_{\mu \theta}{ }^{\prime}\right\} G_{\mu \mu}^{-1} .
$$

In our context, this expression can be simplified. First, $G_{\mu \mu}$ is simply a $4 \times 4$ identity matrix with a negative sign. Second, $S_{\theta \mu}=S_{\mu \theta}{ }^{\prime}=0$. To see this, note that $E\left(h_{\theta i} h_{\mu i}{ }^{\prime}\right)=$ $E\left[E\left(h_{\theta i} h_{\mu i}{ }^{\prime} \mid w_{i}\right)\right]=E\left[E\left(h_{\theta i} \mid w_{i}\right) h_{\mu i}{ }^{\prime}\right]$ by the law of iterated expectation and $h_{\mu i}$ is a function of $w_{i}$. Provided that $w_{i}$ is exogenous, $E\left(h_{\theta i} \mid w_{i}\right)=0$, and thus $S_{\theta \mu}=\lim N^{-1} \sum_{i=1}^{N} E\left(h_{\theta i} h_{\mu i}{ }^{\prime}\right)=$ 0 . The term $G_{\theta \theta}^{-1} S_{\theta \theta} G_{\theta \theta}^{-1}$ is the asymptotic variance of $\widehat{\theta}, V(\widehat{\theta})$. The simplification results in the equation (4). Under the assumption of homoskedasticity or the information matrix equality, $V(\widehat{\theta})$ can be simplified further. We do not make such assumptions in the Monte Carlo simulation and the real-data application in this paper.

The expression (A.1) shows that when $G_{\mu \theta}=\lim N^{-1} \sum_{i=1}^{N} E\left(\partial h_{\mu i} / \partial \theta\right) \neq 0$, as in the case of our study, it is necessary to account for the variability of $\widehat{\theta}$ in the second step. Looking at the opposite way, it reveals why we do not need to take the variability of $\widehat{\tau}$ in estimating $\theta$ and $\mu$. It is easy to verify that $E\left(\partial h_{\theta i} / \partial \tau\right)=0$ and $E\left(\partial h_{\mu i} / \partial \tau\right)=0$, where $\tau=\left(\tau_{1}, \tau_{0}\right)^{\prime}$. Therefore, the variability of $\widehat{\tau}$ does not influence the asymptotic variance of $\widehat{\theta}$ and $\widehat{\mu}$.

\section{B Conditional Expectation Functions}

\section{Variable Definitions and Summary Statistics}


Table B.1: Functional Form

\begin{tabular}{ll}
\hline \hline Model & $F(w ; \theta)$ \\
\hline OLS & $x^{\prime} \beta$ \\
Probit & $\Phi\left(x^{\prime} \beta\right)$ \\
Logit & $\exp \left(x^{\prime} \beta\right) /\left(1+\exp \left(x^{\prime} \beta\right)\right)$ \\
Tobit & $x^{\prime} \beta \Phi\left(x^{\prime} \beta\right)+\sigma \phi\left(x^{\prime} \beta\right)$ \\
Poisson & $\exp \left(x^{\prime} \beta\right)$ \\
Negative Binomial (NB) & $\exp \left(x^{\prime} \beta\right)$ \\
Zero-inflated Poisson ${ }^{a}$ & $\exp \left(x^{\prime} \beta\right) /\left(1+\exp \left(z^{\prime} \gamma\right)\right)$ \\
Zero-inflated NB ${ }^{a}$ & $\exp \left(x^{\prime} \beta\right) /\left(1+\exp \left(z^{\prime} \gamma\right)\right)$ \\
Hurdle Poisson ${ }^{a}$ & $\exp \left(x^{\prime} \beta\right) /\left\{\left(1-\exp \left(-\exp \left(x^{\prime} \beta\right)\right)\right)\left(1+\exp \left(z^{\prime} \gamma\right)\right)\right\}$ \\
Hurdle NB ${ }^{a}$ & $\exp \left(x^{\prime} \beta\right) /\left\{\left(1-\left(1+\alpha \exp \left(x^{\prime} \beta\right)\right)^{-1 / \alpha}\right)\left(1+\exp \left(z^{\prime} \gamma\right)\right)\right\}$ \\
\hline \hline
\end{tabular}

a The regime that leads to a zero outcome is specified by a logit model. That is, $\operatorname{Pr}\left(y_{i}=0 \mid z_{i}\right)=$ $\exp \left(z^{\prime} \gamma\right) /\left(1+\exp \left(z^{\prime} \gamma\right)\right)$. 
Table C.2: Health expenditure ${ }^{\text {a }}$

\begin{tabular}{|c|c|c|c|c|c|}
\hline \multirow{3}{*}{$\begin{array}{l}\text { Number of Obs. } \\
\text { Variables }\end{array}$} & \multirow[b]{3}{*}{ Definition } & \multicolumn{2}{|c|}{ MALE } & \multicolumn{2}{|c|}{ FEMALE } \\
\hline & & \multicolumn{2}{|c|}{9,751} & \multicolumn{2}{|c|}{10,435} \\
\hline & & Mean & Std. Dev. & Mean & Std. Dev. \\
\hline MED & $\begin{array}{l}\text { Annual medical expenditures in } \\
\text { constant dollars excluding dental } \\
\text { and outpatient mental }\end{array}$ & 141.607 & 729.469 & 199.607 & 666.615 \\
\hline LNMED & $\log (\mathrm{MED})$ & 3.928 & 1.445 & 4.262 & 1.501 \\
\hline DMED & 1 if medical expenditures $>0$ & 0.739 & 0.439 & 0.817 & 0.387 \\
\hline $\mathrm{MDU}$ & $\begin{array}{l}\text { number of outpatient visits to a } \\
\text { medical doctor }\end{array}$ & 2.432 & 4.038 & 3.262 & 4.867 \\
\hline $\mathrm{LC}$ & $\begin{array}{l}\ln (\text { coinsurance }+1) \text { with } 0 \leq \text { rate } \\
\leq 100\end{array}$ & 2.377 & 2.041 & 2.390 & 2.042 \\
\hline IDP & $\overline{1}$ if individual deductible plan & 0.255 & 0.436 & 0.265 & 0.441 \\
\hline LPI & $\begin{array}{l}\log \text { (annual participation incen- } \\
\text { tive payment) or } 0 \text { if no payment }\end{array}$ & 4.732 & 2.704 & 4.687 & 2.691 \\
\hline FMDE & $\begin{array}{l}\log (\text { medical deductible expendi- } \\
\text { ture }) \text { if IDP }=1 \text { and } \mathrm{MDE}>1 \text { or } \\
0 \text { otherwise. }\end{array}$ & 4.043 & 3.490 & 4.019 & 3.454 \\
\hline PHYSLIM & 1 if physical limitation & 0.099 & 0.291 & 0.147 & 0.347 \\
\hline NDISEASE & number of chronic diseases & 9.826 & 5.865 & 12.570 & 7.221 \\
\hline HLTHG & 1 if good health & 0.336 & 0.472 & 0.386 & 0.487 \\
\hline HLTHF & 1 if fair health & 0.067 & 0.250 & 0.087 & 0.282 \\
\hline HLTHP & 1 if poor health & 0.010 & 0.101 & 0.019 & 0.137 \\
\hline LINC & log of family income (in dollars) & 8.761 & 1.195 & 8.659 & 1.256 \\
\hline LFAM & $\log$ of family size & 1.276 & 0.530 & 1.223 & 0.546 \\
\hline EDUCDEC & $\begin{array}{l}\text { education of household head (in } \\
\text { years) }\end{array}$ & 12.068 & 2.971 & 11.872 & 2.639 \\
\hline AGE & age & 24.786 & 16.663 & 26.589 & 16.819 \\
\hline CHILD & 1 if age is less than 18 & 0.430 & 0.495 & 0.375 & 0.484 \\
\hline BLACK & 1 if black & 0.167 & 0.371 & 0.196 & 0.393 \\
\hline
\end{tabular}

a Source: Derived from the dataset used in Cameron and Trivedi (2005);

b The numbers of observations with nonzero MED are 7,210 for male and 8,523 for female, respectively. 